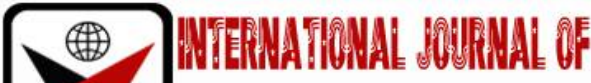

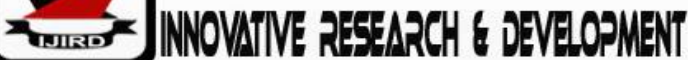

ISSN 2278 - 0211 (Online)

\section{Adaptive Immunity Buildup against Malaria in Comparison to Sars-Cov-2 Fair Resistance in Sub-Saharan Africa}

\begin{tabular}{c}
\hline Bolarin Joshua Adedeji \\
Lecturer, Department of Biochemical Sciences, College of Natural and Applied Sciences, \\
Salem University Lokoja, Kogi State, Nigeria \\
Oluwatoyosi Mercy Adaramodu \\
Research Student, Institute of Botany, Chinese Academy of Science, China
\end{tabular}

\begin{abstract}
:
Currently, the existence of mankind is under a serious threat posed by the spread of novel SARS-CoV-2 (severe acute respiratory syndrome coronavirus 2) also referred to as COVID-2019 [Coronavirus disease 2019] or 2019-nCoV [2019 novel coronavirus].The number of cases across the globe is still on the increase and there has been an urgent need for therapeutic alternatives to alleviate and fight down this pandemic. It is worthy of note that Africa, with high poverty index is still at the base of the countries ravaged by SARS-CoV-2 and this is not far-fetched. Many Africans over the years have been exposed severally to Mosquito bites and malaria infections against which their bodies having been subjected to several doses of different anti-malaria drugs both clinical and traditional (for those who could not afford the cost of clinical drugs) therefore demonstrate strong immunity against SARS-CoV-2; a virus which responds positively to some of the anti-malaria drugs with anti-viral effects such as Chloroquine and Artemisin in widely distributed across Africa. This mini-review aims at providing a quick idea as to the adaptive immunity buildup against malaria by some Africans (mostly in the sub-Saharan region) in comparison to SARS-CoV-2 fair resistance vis-à-vis the effectiveness of supplementing clinical drugs with traditional herbsas a potential solution to this pandemic outbreak.
\end{abstract}

Keywords: SARS-CoV-2, Anti-malaria, Anti-viral, Chloroquine, Artemisinin, Traditional herb, Clinical drug

\section{Introduction}

The existence of mankind has been under constant threat by different emerging infectious diseases like SARS-CoV2 otherwise known as Covid-19 which is currently posing a serious threat. A novel virus which was first discovered in the city of Wuhan, China in early December, 2019 and has continued to gain fast and wide spread across the globe. This virus has been reported to be milder by incubation but more deadly compared to SARS-CoV 2002 and MERS-CoV 2012 [Nature News, 2020]. As of $11^{\text {th }}$ May, 2020, the number of globally confirmed cases and reported death presented by World Health Organization has risen to about 4006257 and 278892 respectively with Europe having about $43.2 \%$ and $56.1 \%$ respectively therefore pegging Europe as the most affected continent of the world. Runner up to Europe is the Americans with $42.5 \%$ confirmed cases and $36.5 \%$ deaths.

However, African continent which is referred to as the poorest has remained the least ravaged continent of the world with $44533(1.1 \%)$ and $1415(0.5 \%)$ confirmed and deaths respectively relative to the global spread of the virus (WHO COVID-2019 situation reports). Since the first reported case of SARS-CoV-2 in Algeria Africa on February $25^{\text {th }} 2020$ after it had been declared a public health emergency of international concern, the number of cases has been increasing in all the African countries except in Lesotho which up till now has reported no case of the virus (Fig 1).So far, several African countries still have below 1000 cases reported, especially countries of the sub-Saharan region of the continent. Worthy of note are countries such as Madagascar, Rwanda, South Sudan, Mozambique, Eritrea, Namibia and Central African Republic with no reported case of death as of $11^{\text {th }}$ May, 2020 despite the rise in the number of confirmed cases; 169, 284, 156, 91, 39,16 and 179 respectively.

The curiosity that may likely arise from this trend of SARS-CoV-2 spread in Africa is the reason the virus has chosen to behave differently with Africans living in African countries as against Africans and Non-Africans living in the other parts of the globe especially in the United State of America. According to the Bureau of Communicable Disease Surveillance System (BCDSS) as of April 2020, a larger parentage of Americans of African descent is affected by the virus and they amount to majority of the recorded death (Fig 2). 


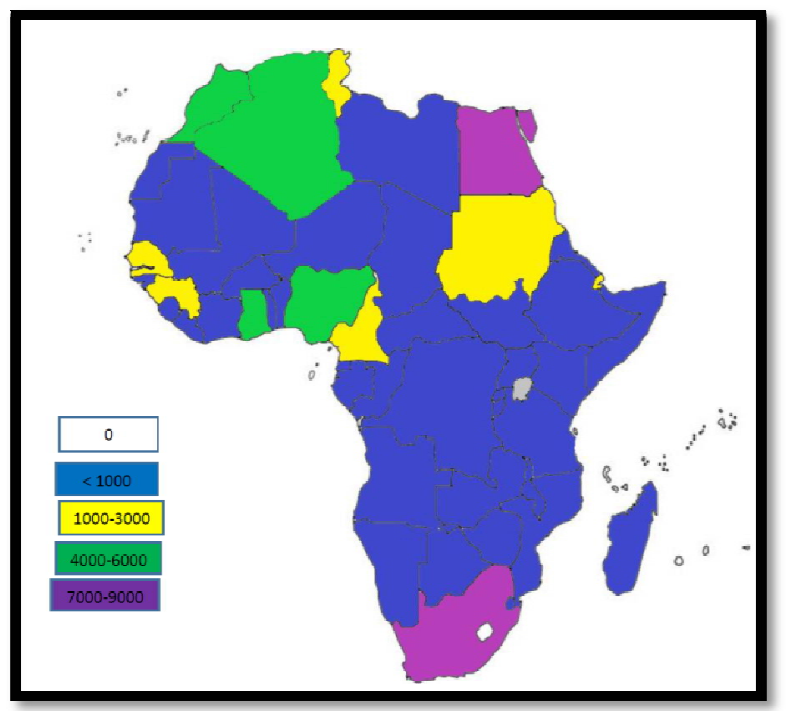

Figure 1: Map of Africa Showing SARS-CoV-2 cases

Furthermore, according to World Health Organization, mostly reported cases of malaria infection occur in Africa especially in the sub-Saharan Africa. This is because a larger percentage of malaria infection in Africa is caused by Plasmodium falciparum which is reported to be the most dangerous of all the four human types of malaria parasite and has accounted for $99.7 \%$ of estimated malaria cases in the sub-Saharan region. Also the responsible malaria vector, Mosquito Anopheles gambiae, has been the most widespread in Africa and the most difficult to control therefore several drugs both traditional and clinical have been widely investigated and consumed by Africans one of drugs being Chloroquine which has been the commonly used anti-malaria drug in African countries to fight down malaria (Trape et al., 1998; Korenromp et al., 2003).

Chloroquine, though initially administered in the treatment and prevention of Malaria in Africa is only effective against Plasmodium vivax, Plasmodium ovale, and Plasmodium malariaebut not against the highly resistant Plasmodium falciparum[Plowe, 2005; Uhlemann and Krishna, 2005]. Due to this high resistance to Chloroquine by Plasmodium falciparum, another effective anti-malaria drug discovered for consumption is called Artemisinin which is basically isolated from the plant Artemisia апnиа(sweet wormwood).Artemisia annuais a plant commonly used in Traditional Chinese Medicineandis equally employed by Africans in the sub-Saharanregion to treat all forms of Malaria infection.The World Health Organization has recommended Artemisin in Combination Therapies (ACT) as the first-line therapy forP. falciparum malaria worldwide [WHO, 2006]. Chloroquine and Artemisinin drugs are readily available in hospitals, pharmaceutical stores, and traditional medicine centers (in the case of Artemisia annua herbal formula) across the continent, meaning that an average African living in Africa most especially in the sub-Saharan region who has been exposed to malaria parasites severallyin a lifetime might have consumed several doses of these anti-malaria drugs at one point or the other.

On $17^{\text {th }}$ February, 2020, the Chinese State Council announced that Chloroquine as it were with combined therapies of Artermisinin can be used in the treatment of SARS-CoV-2 even as researchers/clinicians across China and other parts of the world have earlier investigated into its anti-viral potential [Fredericksen et al., 2002;Savarino et al., 2003; Al-Bari, 2017]. Moreover, Madagascar, a country in the sub-Saharan region of Africa with reported 169 cases and 0 death as stated earlier has been linked with the use of a locally produced traditional formulation called Covid Organic in the treatment of SARS-CoV-2. One of the major components in this formulation was reported to be Artemisia annua; same component used in the production of Artemisinin, an effective anti-malaria drug. These observations point to the reason African countries most especially in the sub-Saharan seem to be reporting fewer cases of SARS-CoV-2 infections and deaths than those obtainable in other parts of the world as most Africans living in Africa especially the sub-Saharanover the years have been exposed continually to several doses of traditional herbs or processed pills including Chloroquine, Artemisinin or plant Artemisia annua and as a result, their immune systems have fairly developed resistance against fierce SARS-CoV-2. Also, these facts are a pointer to the effectiveness of adopting combined therapies both clinical and traditional medicines in the fight against SARS-CoV-2. 


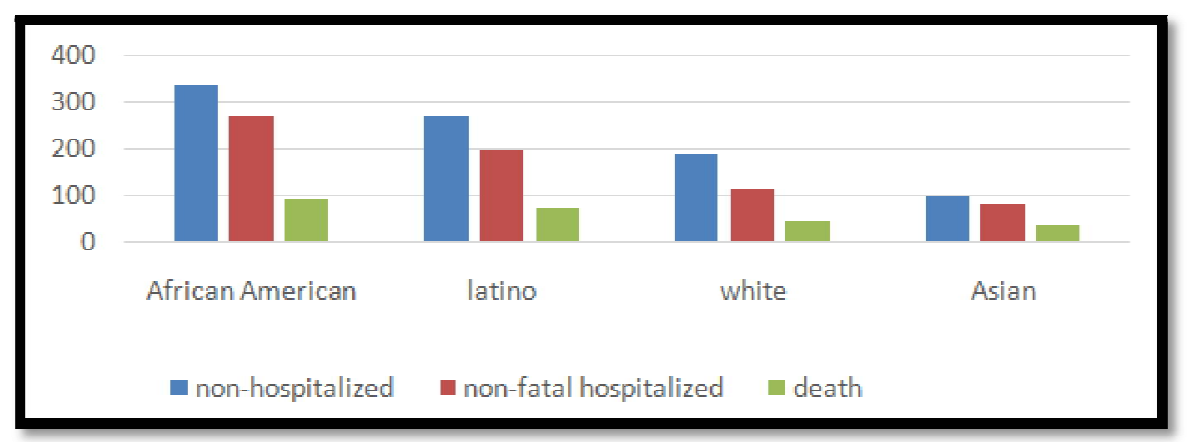

Figure 2: Distribution of Races as Affected by SARS-Cov-2 Source: New York City Department of Health and Mental Hygiene

Apart from the aforementioned anti-malaria agents with anti-viral properties, there are other active anti-malaria agents with anti-viral properties which most Africans fall back to when infected with Malaria. One of these is the plant Azadirachta indica commonly referred to as Neem plant. This plant has been used in the treatment of different diseases including inflammation, infections, fever, skin diseases, and viral infections (Subapriya and Nagini, 2005).

Also according to Mahmood et al., 2010, Lipipun et al., 2003, Virmani and Garg, 2005, Moringa oleifera, aplant belonging to the family Moringaceae also known as Moringa plant has antiviral, antidiuretic, antipyretic, anticancer, antiinflammatory, and antibacterial properties. All the parts of Moringa plant including the root, bark, gum, fruit and flower are used in the production of traditional medicines (Anwar et al., 2007). The leaves and pods contain vitamin C, carotene, calcium, potassium, flavonoids and phenol which function both as antioxidant and antiviral agents. Moringa has been widely used in the treatment of yellow fever and polio virus (Okoye, 2014).

However, the points of concern aboutthe use of Chloroquine drug in fighting SARS-CoV-2are the side effects which include itching, abdominal discomfort, nausea, vomiting, and diarrhea (Goodman and Gilman, 2011). Excessive use of this anti-malaria/anti-viral drug can lead to neurological disorder such as mental confusion, seizures, and coma, and cardiovascular symptoms such as hypotension, vasodilation, suppression of myocardial function, and cardiac arrhythmias. It has been reported that excess Chloroquine in the blood stream may block the entrance of potassium into the cells (Wagner et al., 2010). Currently, little is known on the possible side effects that might arise from the use of antimalarial as treatment for SARS-CoV-2 but the risk of the aftereffects on malaria treatment might be devastating especially in subSahara African countries. Therefore, much more investigations should be tailored towards the use of traditional herbs than clinical medications as a way out of SARS-CoV-2. Medicinal plants and herbs are not fully understood and in light of this, several clinical trials on Artemisia annua and other herbs are currently going on to evaluate their effects and to know if truly these plants will be the way out of the current pandemic or not. Apart from observable decrease in the number of reported SARS-CoV-2 cases in Madagascar after using the traditionally formulated herbal medication, the use of Traditional Chinese Medication (TCM) in the fight against SARS-CoV 2002, MARS-CoV 2012 and in the treatment of SARSCoV-2 are enough evidences to prove that traditional medication might be the way forward (Zhong et al., 2004; JSM, D P, Yuen, 2003; Jr TMF \& Tsang, 2005).

In addition to this, the spontaneous decrease in the fatality rate of SARS-CoV-2 patients in China as at $11^{\text {th May, }}$ 2020 is attributed to the use of Traditional Chinese Medication as a supplement to the normal clinical therapy. There is need for a multidisciplinary approach towards identifying and characterizing potential anti-viral compounds as therapeutic alternatives both clinically and traditionally which is highly required now than ever to curtail this current pandemic outbreak.

\section{Conflicts of Interest}

There are no conflicts of interest among the authors.

\section{References}

i. Al-Bari, M.A (2017). "Targeting endosomal acidification by chloroquine analogs as a promising strategy for the treatment of emerging viral diseases". Pharmacology Research \& Perspectives. 5 (1): e00293. Doi:10.1002/prp2.293. PMC 5461643. PMID 28596841.

ii. Anwar, F., Latif, S., Ashraf, M., Gilani, A.H (2007). Moringa Oleifera: A Food Plant with Multiple Medicinal Uses. Phytotherapy Research, 21(1): 17-25.

iii. Fredericksen, B.L., Wei, B.L., Yao, J., Luo, T., Garcia, J.V (2002). "Inhibition of endosomal/lysosomal degradation increases the infectivity of human immunodeficiency virus". Journal of Virology. 76 (22): 114406. Doi:10.1128/JVI.76.22.11440-11446.2002. PMC 136743. PMID 12388705

iv. Goodman, L.S and Gilman, A.G (2011). As bases pharmacological da 'therapeutic McGraw-Hill Medical, Rio de Janeiro, Brazil, 12th edition.

v. Guidelines for the Treatment of Malaria. Geneva: World Health Organization. 2006. ISBN 978-92-4-154694-2.

vi. https://www.nytimes.com/2020/04/01/health/hydroxychloroquine-coronavirus-malaria.html

vii. https://www.vox.com/coronavirus-covid19/2020/4/18/21226225/coronavirus-black-cdc-infection

viii. https://www.who.int/news-room/fact-sheets/detail/malaria

ix. Jr TMF, Tsang KWT (2005). Severe Acute Respiratory Syndrome. Nat Med. 4:95-106.

x. JSM P, D P, Yuen KY, (2003). The Severe Acute Respiratory Syndrome. New Engl J Med. 249:2431-41. 
xi. Korenromp, E.L., Williams, B.G., Gouws, E., Dye, C., Snow, R.W (2003). Measurement of trends in childhood malaria mortality in Africa: an assessment of progress towards targets based on verbal autopsy. Lancet Infect Dis 3: 349-58.

xii. Lipipun, V., Kurokawa, M., Suttisri, R., Taweechotipatr, P., Pramyothin, P.,Hattori, M and Shiraki, K (2003). Efficacy of Thai medicinal plant extracts against herpes simplex virus type 1 infection in vitro and in vivo. Antivir. Res., 60: 175-180.

xiii. Mahmood K.T, Mugal T and Haq I (2010). Moringa oleifera: A natural gift-A review. J. Pharmac. Sci. Res., 2: 775781.

xiv. Nature News. Coronavirus latest: death toll passes 2,000. Available from: https://www.nature.com/articles/d41586-020-00154-w (Accessed on 20 Feb 2020).

xv. Okoye, E.L (2014). Inhibition of The Poliomyelitis Viral-Induced Cytopathic Effect by Extracts of Moringa Oleifera Lam. Australian Journal of Herbal Medicine, 26(3): 95

xvi. $\quad$ Plowe, C.V (2005). "Antimalarial drug resistance in Africa: strategies for monitoring and deterrence". Malaria: Drugs, Disease and Post-genomic Biology. Current Topics in Microbiology and Immunology. 295. pp. 5579. Doi:10.1007/3-540-29088-5_3. ISBN 3-540-25363-7. PMID 16265887.

xvii. Savarino, A., Boelaert, J.R., Cassone, A., Majori, G., Cauda, R (2003). "Effects of chloroquine on viral infections: an old drug against today's diseases?" The Lancet. InfectiousDiseases. 3 (11):7227. Doi:10.1016/s14733099(03)008065. PMC 7128816. PMID 14592603.

xviii. Subapriya, R., Nagini, S (2005). Medicinal properties of Neem leaves: a review. Curr Med Chem Anti Canc Agents $5,149-56$.

xix. Trape, J.F., Pison, G., Preziosi, M.P., Enel, C., Desgrées du Loû, A., Delaunay, V., (1998). Impact of chloroquine resistance on malaria mortality. C R Acad Sci Paris 321: 689-97.

xx. Uhlemann, A.C., Krishna, S (2005). "Antimalarial multi-drug resistance in Asia: mechanisms and assessment". Malaria: Drugs, Disease and Post-genomic Biology. Current Topics in Microbiology and Immunology. 295. pp. 39-53. Doi:10.1007/3-540-29088-5_2. ISBN 3-540-25363-7. PMID 16265886.

xxi. Virmani, M and Garg, S (2005). In vitro antiviral activity of plant extracts against equine herpes virus-1. Indian J. Microbiol, Immunol. Infect. Dis., 26: 89-91.

xxii. Wagner, M., Riepe K.G., Eberhardt, E., Volk, T (2010). “Open channel block of the fast transient outward K+ current by primaquine and chloroquine in rat left ventricular cardiomyocytes," European Journal of Pharmacology, vol. 647, no. 1-3, pp. 13-20.

xxiii. World Health Organization. Coronavirus disease (COVID-2019) situation reports. Available from:https://www.who.int/emergencies/diseases/novel-coronavirus-2019/situation-reports (Accessed 2020).

xxiv. Zhong,N., May, R.M., McLean, A.R., Pattison, J., Weiss, R.A (2004). Management and prevention of SARS in China. Philos Trans R Soc Lond B Biol Sci. 359:1115-6. 